\title{
Finding a middle way to sustainable food systems
}

\author{
Review by D anielle Robinson * \\ University of Guelph
}

Review of G ood A pples: Behind E very Bite, by Susan Futrell. (2017). Published by University of Iowa Press. Available as paperback and ebook; 262 pages. Publisher's website: https:/ / www.uipress.uiowa.edu/ books/9781609384821/ good-apples

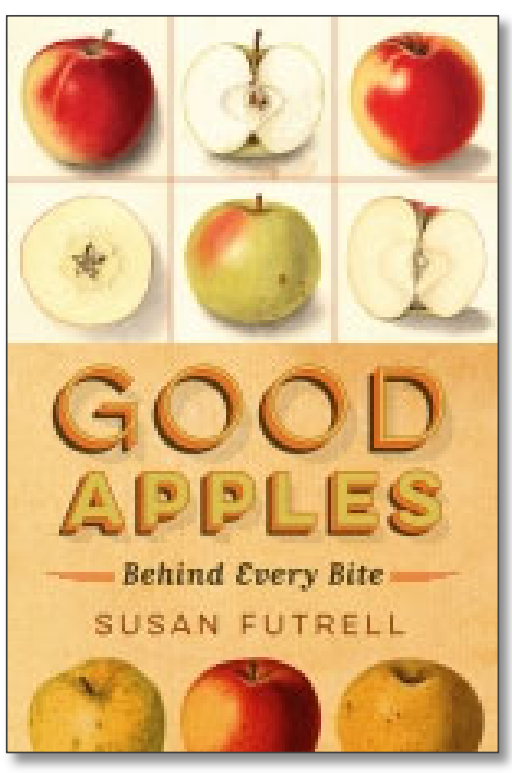

Submitted November 6, 2018 / Published online February 13, 2019

Citation: Robinson, D . (2019). Finding a middle way to sustainable food systems [Book review]. Journal of A griculture, Food Systems, and C ommunity D evelopment, 8(4), 211-213. https:/ / doi.org/ 10.5304/ jafscd.2019.084.015

Copyright @ 2019 by the Author. Published by the Lyson Center for Civic Agriculture and Food Systems. Open access under CC-BY license.

$\mathrm{T}_{\mathrm{s}}^{\mathrm{s}}$ he premise of Susan Futrell's G ood A pples: Behind $\mathrm{E}$ very Bite is that by understanding the environmental, social, and economic issues affecting apples growers in America, the reader can better appreciate and support sustainable food systems. Futrell's storytelling is grounded in her years of experience working in sustainable food distribution, which includes 25 years in sales and marketing for a cooperatively owned natural food distributor called Blooming Prairie Warehouse in the Midwest, and her current work with Red Tomato, a small nonprofit food hub based in

* D anielle Robinson is a Ph.D. candidate in the School of Environmental D esign and Rural D evelopment at the University of Guelph. She also teaches courses related to food, wine, and tourism at Okanagan College in British Columbia. Her research interests include food sovereignty, cultural sustainability, and rural tourism. She can be reached at drobin11@ uoguelph.ca or drobinson@ okanagan.bc.ca.
Massachusetts, where she helped develop the Eco Apple ${ }^{\circledR}$ program.

From the beginning, Futrell resists the pressure to simplify and dichotomize complexities. Chapter 1 , A t the Intersection of A pples and L ocal, establishes this tone with her contextual consideration of how the term local is defined. Chapter 2, Immigrant A pples, reviews the history of apples in America. In it she discusses key historical figures and the emergence of seedling nurseries, apple varieties, growers' associations, and land-grant institutions.

In Chapter 3, The People $\mathrm{W}$ ho $\mathrm{G}$ row the A pples W eE at, Futrell introduces a diverse cast of apple growers from across the United States: from organic to conventional, from Connecticut to Washington state, and from first-generation to long-established farming families. The stories shared by these small and midsized growers are used throughout the book, along with the work of 
sustainability thinkers like Rachel Carson (1962), Aldo Leopold (1949/ 1970) and Wendell Berry (1977), contemporary food writers like Michael Pollen (2006), and a variety of agricultural resources.

The fourth chapter, Making A pples, explores the myriad decisions involved in planting, pruning, managing pests and disease, harvesting, packing, shipping, and storing apples. The factors affecting these decisions are complex, ranging from geographic suitability to market appeal. Chapter 5, $G$ rafting Remnants, serves as transition from the past to the present as the concept of grafting is considered literally and figuratively in relation to how knowledge about apples is passed between generations.

Chapter 6, G ive the People W hat They W ant, covers how apples are bred to meet consumers' tastes and the need for efficient, predictable yield. As the case of Red D elicious apples demonstrates, this unfortunately has meant progressively redder, firmer, but less flavorful apples. Chapter 7, Keeping the Farm, illuminates how agricultural and economic changes have shifted economic and market power away from growers and local markets. These issues and trends are examined further in Chapter 8, The E nterprise of A pples for Sale, which discusses how the pressure to cut costs has reduced apple diversity and centralized control. The strategies to deal with the pressure for profitability have centered on "'get big, get niche, or get out.'” In Chapter 9, W orking A pples, Futrell argues that the treatment of agricultural workers intersects issues of race, economics, and immigration politics. A gain, Futrell cautions against the trap of antagonistic dichotomies like farmers versus workers, white versus of color, citizen versus immigrant, but encourages the reader to focus on the common goals like workforce development and farm sustainability.

In chapter 10, Pests and Public Scienœ, Futrell treats controversial issues of pest management with a similar curiosity and sensitivity. She describes the history of pesticide use, as well as biological and ecological approaches central to organic and Integrated Pest Management (IPM). O rganic and IPM approaches are further explored in Chapter eleven, $M$ ark eting the Ideal, using the Alar case of the late 1980s that focused media and public attention on the effects of the daminozide pesticide on children. The case marked a powerful cultural shift and resulted in national organic standards but damaged the relationship between the environmental community and apple farmers. Finally, in her closing chapter, A D emocracy of A pples, Futrell makes clear her call for a middle way "that might more quickly reduce the most egregious harm and find workable solutions over time for the rest" (p. 199).

$\mathrm{G}$ ood A pples gives voice to farmers on small and midsized family farms and those who grow, pick, study, buy, and sell apples. Although Futrell emphasizes that "their stories are not quick sounds bites" (p. 16), she has a good ear for memorable, honest quotes and finds the commonalities and themes within diverse experiences. She deals with the intricacies and challenges of growing and selling apples- like the risks of fruit rot and brown marmorated stink bug (BMSB) - but does not shy away from the bigger questions about why this all matters. Issues like climate change, equity, and democracy are larger than apples, the agriculture industry, or any individual country, and so although it is written from an American perspective, this book would appeal to any reader who is concerned "about the kind of ecosystem, economy and values we are creating for ourselves and for the next generation" (p. 220).

Futrell takes an appreciative, nuanced approach and stresses the need to consider both what needs to be changed and what needs to be understood and valued. She advocates reframing food as a public good collectively determined through a democratic process characterized by interdependence, diversity, resilience, and respect for philosophical differences. Apples' historic role could be treated more critically, given that although Henry Ward Beecher called apples "the true democratic fruit" they have also been tools of colonization. This is dramatically exemplified by the consequences of major projects like the $\mathrm{G}$ rand Coulee D am, which provides irrigation for extensive apple orchards in Washington state by having flooded over 20,000 acres (8,100 hectares) of land that Indigenous people lived and hunting on for millennia (Harden, 1996). Working through a democratic process needs to include critical food-systems alternatives. Food sovereignty movements 
dedicated to decolonization and Indigenous revitalization (Figueroa-Helland, Thomas, \& Aguilera, 2018; Grey \& Patel, 2015; Skinner, Martens, Cidro, $\&$ Burnett, 2018) and feminist agroecological approaches (Shiva, 2016) could provide important perspective.

$\mathrm{G}$ ood A pples is a poetic call for collective action that seeks a middle way. Futrell convincingly argues that the future of family orchards and democracy depends on working together. She is "fierce about standing in the middle" (p. 208), where complexity replaces certainty, because neither extreme, giantscale, industrialized agriculture or microscale local agriculture can address all the complexities and interconnections. Futrell's position reflects Meadow's (2008) advice for living in a world of systems: stay humble, stay a learner, and celebrate complexity. In many ways, the greatest strengths of $\mathrm{G}$ ood A pples - its open-mindedness and optimistic humility - are also its greatest weaknesses since, as Futrell recognizes, appreciative, inquiry-based moderation “doesn't fundraise as well as the rallying cry of the certain" (p. 196). G ood A pples: Behind $E$ very Bite manages to be both idealistic and realistic about food systems' change. That is a paradox I suspect Futrell would appreciate.

\section{References}

Berry, W. (1977). The agriaultural crisis: A crisis of alture. Great Barrington, MA: Myrin Institute.

Carson, R. (1962). Silent spring. Boston: Houghton Mifflin.

Figueroa-Helland, L., Thomas, C., \& Aguilera, A. P. (2018). D ecolonizing food systems: Food sovereignty, indigenous revitalization, and agroecology as counter-hegemonic movements. Perspectives on $\mathrm{G}$ lobal D evelopment and Technology, 17(1-2), 173-201. https:/ / brill.com/ view/ journals/ pgdt/ pgdt-overview.xml

Grey, S., \& Patel, R. (2015). Food sovereignty as decolonization: Some contributions from Indigenous movements to food system and development politics. A griculture and $\mathrm{H}$ uman V alues, 32(3), 431-444. https:// doi.org/ 10.1007/ s10460-014-9548-9

Harden, B. (1996). A River L ost: The life and death of the C olumbia. New Y ork: W.W. Norton.

Leopold, A. (1949/ 1970). A Sand County almanac. New York: Ballantine.

Meadows, D . H. (2008). Thinking in systems: A primer. White River Junction, VT: Chelsea Green Publishing.

Pollan, M. (2006). The omnivore's dilemma: A natural history of four meals. New Y ork: Penguin.

Shiva, V. (2016). W ho really feeds the world? The failures of agribusiness and the promise of agroeoology. Berkeley, CA: North Atlantic Books.

Skinner, K., Martens, T. R., Cidro, J., \& Burnett, K. (2018). From bitter to sweet: Continuing the conversation on Indigenous food sovereignty through sharing stories, engaging communities, and embracing culture. $\mathrm{C}$ anadian $\mathrm{F}$ ood Studies / L a Revue canadienne des études sur l'alimentation, 5(2), 3-8. https:/ / doi.org/ 10.15353/ cfs-rcea.v5i2.323 